\title{
A glimpse towards cultivable hemolymph microbiota of marine crabs: Untapped resource for aquatic probiotics/antibacterial agents
}

\author{
T.G. Sumithra ${ }^{a}$, K.J. Reshma ${ }^{\mathrm{a}, *, 1}$, J.P. Christo ${ }^{\mathrm{a}}$, V.N. Anusree ${ }^{\mathrm{a}}$, D. Drisya ${ }^{\mathrm{a}}$, T.G. Kishor ${ }^{\mathrm{b}}$, \\ D.N. Revathi ${ }^{\mathrm{a}}$, N.K. Sanil ${ }^{\mathrm{a}}$ \\ ${ }^{a}$ Marine Biotechnology Division, ICAR-Central Marine Fisheries Research Institute, Post Box No. 1603, Ernakulam North P.O, Kochi 682 018, India \\ ${ }^{\mathrm{b}}$ Fishery Resources Assessment Division, ICAR-Central Marine Fisheries Research Institute, Post Box No. 1603, Ernakulam North P.O, Kochi 682 018, India
}

A R T I C L E I N F O

\section{Keywords:}

Portunus pelagicus

Charybdis feriatus

Portunus sanguinolentus

Charybdis lucifera

\begin{abstract}
A B S T R A C T
Bacterial diseases have turned out to be the primary constraint in sustainable aquaculture production, where, probiotics can play an important role to prevent or control fish and shellfish diseases. As the autochthonous preparations would be more effective than commercial products, continued search for novel antibacterial strains native to aquatic environment are warranted against aquatic pathogens. Further, knowledge on abundance, composition and role of hemolymph microbes is also essential to predict the health status and disease diagnosis. Hence, in present study, 4 commercially significant marine crabs that are important for aquaculture were used to unravel the implication and significance of cultivable hemolymph microbes. Bacterial abundance was found to be individual- and species-dependent; and statistically significant interaction was present between growth media and abundance. Gram negative isolates represented $84 \%$ of hemolymph microbes. Vibrio was the principal genera in all species; each carrying a specific hemolymph microbiota (both in terms of abundance and diversity). The present study forms the first report of genera viz., Enterovibrio, Pantoea, Kluyvera and Enterobacter in crustacean hemolymph. Interestingly, new Vibrio species were also found. Further, the study forms the first observation on inhibitory activity of marine crab hemolymph microbes against aquatic pathogens. Overall, the results highlight marine crab hemolymph microbiota as a promising moreover, an untapped resource for probiotics/antimicrobial agents to combat aquatic pathogens. Concurrently, the present study fetches a platform for the prediction of health and disease diagnosis of 4 potentially important aquaculture crab species.
\end{abstract}

\section{Introduction}

Crustacean fishery makes a noteworthy impact to the global food security and livelihoods of people living in coastal areas (BondadReantaso et al., 2012). Among marine crustaceans, crabs occupy significant position in terms of export potential and nutritional value (Varadharajan and Soundarapandian, 2014). As vast majority of wild fish/shellfish stocks are fully or overfished with no room for further expansion of commercial fishing efforts (FAO, 2014); aquaculture under controlled intensive conditions might be a solution to meet the increasing global demand. Therefore, an increased interest has aroused on the research related to crab diseases, immunity and pathogen epidemiology reflected by the recent surge of related publications (Wang et al., 2015).

While the presence of microorganisms in hemolymph of apparently healthy crustaceans has been confirmed in selected species (Tubiash et al., 1975; Kaizu et al., 2011; Ponprateep et al., 2012; Wang et al., 2014), little data is available on the hemolymph microbes of tropical marine crabs. Even though hemolymph associated microbiota in targeted crab species has been screened for human pathogens (Sizemore et al., 1975; Davis and Sizemore, 1982; Faghri et al., 1984; Rivera et al., 1999), its composition and role within the host remain obscure. Knowledge on natural bacterial populations in hemolymph of healthy crabs will be helpful to reveal host immunity, pathogenesis, and diagnosis (Gomez-Gil et al., 2010; Wang et al., 2015). Further, efficacy of probiotics is reported to be highest in the host species from where they were isolated (Verschuere et al., 2000). Accordingly, searching microbes from commercially significant marine crab species against aquatic pathogens will be helpful in developing autochthonous probiotics for the farming of these animals. Very recently, Zhang et al.

\footnotetext{
* Corresponding author.

E-mail address: sumithra.G@icar.gov.in (K.J. Reshma).

${ }^{1}$ Present address: Scientist, Marine Biotechnology Division, ICAR- Central Marine Fisheries Research Institute, Post Box No. 1603, Ernakulam North P.O., Kochi682018.
} 
(2018) revealed real abundances and diversity of hemolymph microbiota in three aquatic invertebrates (Scylla paramamosain, Litopenaeus vannamei and Crassostrea angulata) through a new cell extraction method. However, as they followed culture independent method they could not determine the role of these hemolymph microbes and could not point out any potential isolates for future applications. Considering all these aspects, an attempt was made to elucidate the abundance, diversity and role of hemolymph microbiota in four commercially significant marine crab species through culture dependent methods.

\section{Material and methods}

\subsection{Sampling of crabs}

Three batches of four commercially significant marine crab species (Fig. 1) were collected using trawl nets. Three sites were sampled in 3 phases from Cochin coast, Kerala, India (Fig. 1; Table 1) to account for the variations in bacterial diversity due to geographical location and environmental conditions. Hydrographic parameters such as depth, temperature (sea surface temperature, SST and atmospheric temperature, AT), salinity, $\mathrm{pH}$, and turbidity were estimated at each collection site by a hand held multi-parameter tester (Eutech, Singapore). Dissolved oxygen (DO) was measured by Winkler's method (Winkler, 1888). The animals were retained in sterile polythene bags containing autoclaved sea water ( 3 crabs per 2 Liter). The bags were then placed in clean thermocol boxes containing ice packs, brought to laboratory immediately after collection (within $1 \mathrm{~h}$ ), and crabs were not fed during transport (Gomez-Gil et al., 2010). A total of 9 apparently healthy marine crabs from each species were selected and weight $(\mathrm{W})$ and carapace width (CW) were recorded. All animals were anaesthetized on ice and external surfaces especially, base of periopods were disinfected with $70 \%$ ethanol before collection of hemolymph, to prevent contamination with surface bacteria (Colwell et al., 1975). Approximately, $200 \mu \mathrm{l}$ of hemolymph was aseptically withdrawn from each animal.

All crabs in present study were handled according to the recommended EU Directive 2010/63/EU for animal experiments and the practice was approved by ICAR- Central Marine Fisheries Research Institute, Kochi, India.

\subsection{Enumeration of culturable hemolymph bacteria}

The collected hemolymph was serially diluted and spread onto Zobell Marine Agar (ZMA), Brain Heart Infusion Agar (BHIA) and Thiosulphate Citrate Bile-salt Sucrose Agar (TCBS) (Himedia, India) plates. The plates were incubated at $30^{\circ} \mathrm{C}$ and were examined up to 5 days (Hovda et al., 2007). Total viable count was expressed as log colony forming units per $\mathrm{ml}$ of hemolymph ( $\left.\log _{10} \mathrm{CFU}\right)$. Viable counts of presumptive vibrios (mesophilic Vibrionaceae and other closely related vibrios) were recorded after 5 days of incubation on TCBS agar (Bolinches et al., 1988).

\subsection{Diversity and phylogenetic analysis of culturable bacteria in hemolymph}

Morphologically unique colonies from each dilution were selected for purification and characterized by conventional microbiological tests and 16SrRNA gene sequencing. All the purified cultures were stored as agar slants at $4{ }^{\circ} \mathrm{C}$ and as glycerol stocks at $-80^{\circ} \mathrm{C}$. For characterization by $16 \operatorname{SrRNA}$ gene sequencing, the gene was amplified from each purified culture using universal primers (Nair et al., 2012) and was sequenced at Scigenom, India. The sequence data were edited and compiled with Editseq (DNASTAR, Lasergene, USA). For preliminary identification, the obtained 16SrRNA gene sequences were compared with those in GenBank database, National Center for Biotechnology Information (NCBI) using nucleotide BLAST with default parameters. Sequence identities of $97 \%$ and $99 \%$ were taken as the benchmarks for genus and species assignments, respectively (Janda and Abbott, 2007).

The results of characterization by $16 \operatorname{SrRNA}$ gene sequence were then compared with that of conventional microbiological tests (Bergey et al., 2012) for final identification of bacteria. Further, in case of Vibrio sp. the protocol by Noguerola and Blanch (2008) was followed to verify the species. The isolates showing contradiction between the results of microbiological and molecular characterization were consigned as novel species. Subsequently, the representative 16SrRNA gene sequences were deposited in GenBank.

Subsequently, the overlapping $771 \mathrm{bp}$ sized fragment of $16 \mathrm{SrRNA}$ gene sequences were aligned using CLUSTAL W and the aligned data set was used as input for phylogenetic analysis. Phylogenetic analysis was
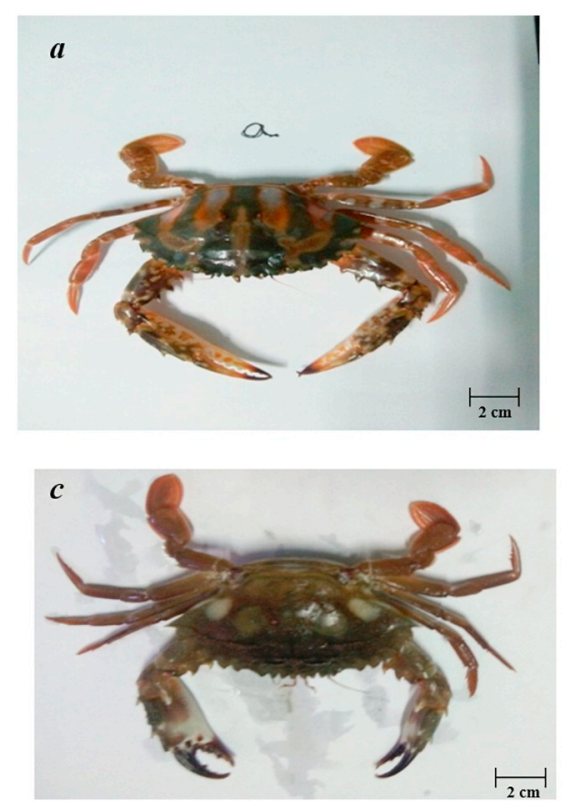

Fig. 1. Sampling sites and crabs under study.

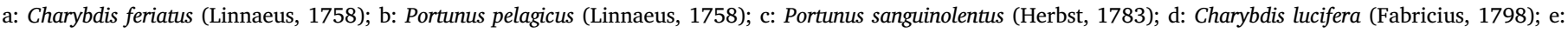
Sampling sites.
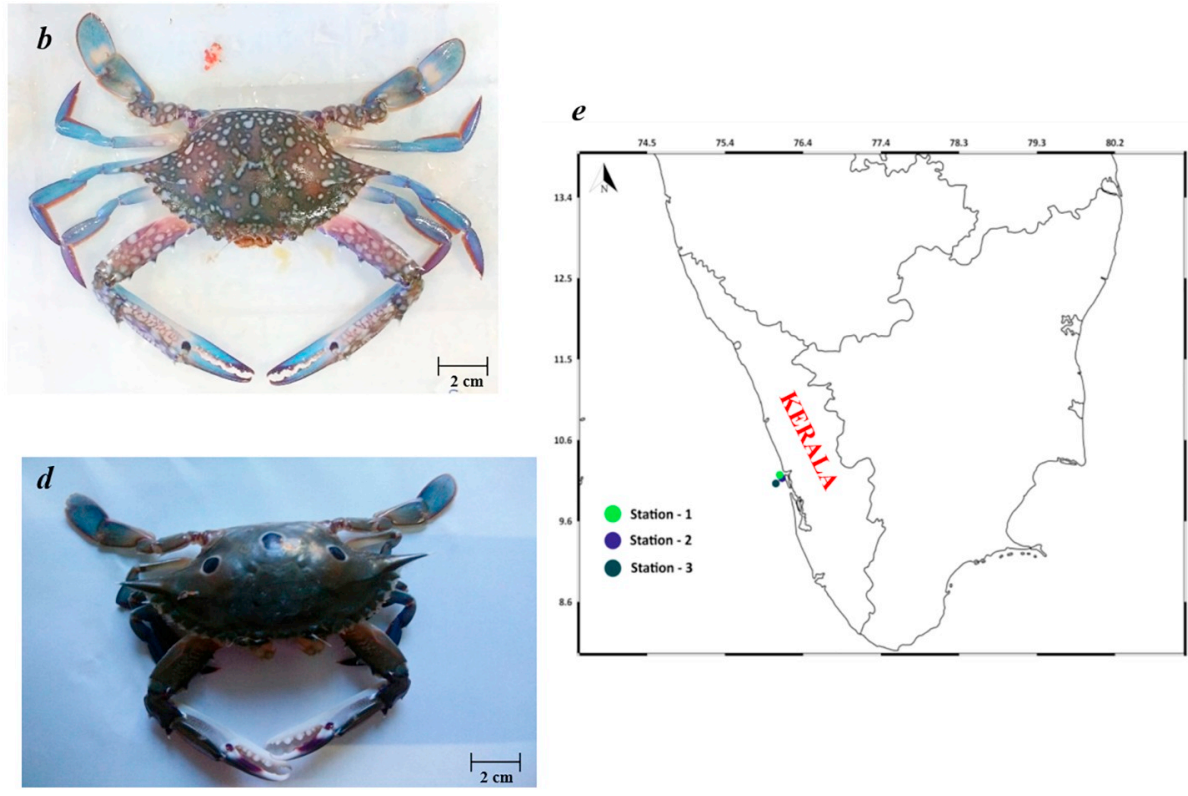
Table 1

Sampling sites, hydrographic parameters and morphometrics of crabs under study.

\begin{tabular}{|c|c|c|c|c|c|c|c|c|c|c|}
\hline \multirow[t]{2}{*}{ Sampling sites and dates } & \multirow{2}{*}{$\begin{array}{l}\text { Coordinates } \\
\text { Date }\end{array}$} & \multicolumn{3}{|c|}{$10^{\circ} 07^{\prime} \mathrm{N} 76^{\circ} 09^{\prime} \mathrm{E}$} & \multicolumn{3}{|c|}{$10^{\circ} 09^{\prime} \mathrm{N} 76^{\circ} 05^{\prime} \mathrm{E}$} & \multicolumn{3}{|c|}{$10^{\circ} 03^{\prime} \mathrm{N} 76^{\circ} 04^{\prime} \mathrm{E}$} \\
\hline & & \multicolumn{3}{|c|}{ 05-12-2016 } & \multicolumn{3}{|c|}{ 25-12-2016 } & \multicolumn{3}{|c|}{ 07-1-2017 } \\
\hline \multirow[t]{7}{*}{ Hydrographic parameters } & Depth (m) & 20 & & & 20 & & & 15 & & \\
\hline & Salinity (ppt) & 35 & & & 35 & & & 35 & & \\
\hline & $\operatorname{AT}\left({ }^{\circ} \mathrm{C}\right)$ & 30 & & & 30 & & & 30 & & \\
\hline & $\mathrm{DO}(\mathrm{ppm})$ & 7.3 & & & 7.2 & & & 7.1 & & \\
\hline & $\mathrm{pH}$ & 7.4 & & & 7.3 & & & 7.2 & & \\
\hline & Turbidity (ntu) & 1.18 & & & 1.26 & & & 1.21 & & \\
\hline & SST $\left({ }^{\circ} \mathrm{C}\right)$ & 28 & & & 29 & & & 28 & & \\
\hline \multirow[t]{4}{*}{ C. feriatus (Linnaeus, 1758) under study } & ID & 1 & 2 & 3 & 4 & 5 & 6 & 7 & 8 & 9 \\
\hline & Sex & M & $\mathrm{F}$ & M & $\mathrm{F}$ & M & M & M & M & $\mathrm{F}$ \\
\hline & W (g) & 62 & 41 & 50 & 36 & 72 & 73 & 32 & 63 & 38 \\
\hline & $\mathrm{CW}(\mathrm{cm})$ & 8 & 7 & 7 & 6.5 & 8 & 7.5 & 6 & 7 & 6 \\
\hline \multirow{4}{*}{ P. pelagicus (Linnaeus, 1758) under study } & ID & 1 & 2 & 3 & 5 & 6 & 7 & 8 & 9 & 10 \\
\hline & Sex & $\mathrm{F}$ & M & M & M & $\mathrm{F}$ & M & $\mathrm{F}$ & $\mathrm{M}$ & M \\
\hline & W (g) & 35 & 64 & 73 & 55 & 40 & 45 & 50 & 66 & 48 \\
\hline & $\mathrm{CW}(\mathrm{cm})$ & 6 & 10 & 11 & 9.5 & 8 & 9 & 9 & 10 & 9 \\
\hline \multirow[t]{4}{*}{ P. sanguinolentus (Herbst, 1783) under study } & ID & 1 & 2 & 3 & 4 & 5 & 6 & 7 & 8 & 9 \\
\hline & Sex & $\mathrm{M}$ & M & $\mathrm{F}$ & M & $\mathrm{F}$ & $\mathrm{M}$ & $\mathrm{M}$ & $\mathrm{M}$ & $\mathrm{F}$ \\
\hline & W (g) & 30 & 53 & 33 & 36 & 28 & 56 & 52 & 55 & 51 \\
\hline & $\mathrm{CW}(\mathrm{cm})$ & 8.5 & 10 & 7 & 7.5 & 8 & 10 & 9.0 & 9.5 & 9 \\
\hline \multirow[t]{4}{*}{ C. lucifera (Fabricius, 1798) under study } & ID & 1 & 2 & 3 & 4 & 5 & 6 & 7 & 8 & 9 \\
\hline & Sex & $\mathrm{F}$ & M & M & M & M & $\mathrm{F}$ & M & $\mathrm{F}$ & M \\
\hline & $\mathrm{W}(\mathrm{g})$ & 36 & 80 & 52 & 83 & 37 & 30 & 55 & 50 & 48 \\
\hline & $\mathrm{CW}(\mathrm{cm})$ & 6 & 8 & 7 & 8 & 6 & 5 & 7 & 7 & 7.5 \\
\hline
\end{tabular}

done using Molecular Evolutionary Genetics Analysis, version 7 (MEGA 7) using Kimura 2-parameter model (Kumar et al., 2016). Tree topology was estimated by bootstrap analyses based on 1000 replicates, and phylogenetic tree was constructed using neighbor-joining (NJ) method.

\subsection{Antimicrobial assay}

Each hemolymph associated bacteria were assayed in-vitro for antibacterial activity against a panel of 11 indicator strains of aquatic pathogens (Table 3) by spot diffusion assay (Nair et al., 2012). Briefly, $8 \mathrm{~h}$ old cultures of these indicator strains $\left(10^{6} \mathrm{CFU} / \mathrm{ml}\right)$ were spread separately onto the surface of Mueller Hinton Agar media (HiMedia) (with or without $1 \% \mathrm{NaCl}$ supplementation according to pathogen). Later, pure culture of each isolate was spotted onto these agar plates. The plates were examined for the formation of inhibitory zone after overnight incubation at $30^{\circ} \mathrm{C}$. Zone was recorded and measured for positive isolates. The test was replicated for positive cases to confirm the antimicrobial activity and the mean zone diameter was taken for analysis. Versatility of each isolates and number of positive isolates against each pathogen were also noted down. Scoring of positive isolates based on their zone of inhibition diameter (difference between total zone diameter and bacterial colony diameter) was also done (Nandi et al., 2017) in which score 4, 3, 2, 1 and 0 were assigned to very high (>15 mm), high (10-14 mm), moderate (5-9 mm), Low, (1-4 mm) and no inhibition activities respectively.

\subsection{Statistical analysis}

Two-way ANOVA (SPSS software program ver. 16) followed by Turkey test was used to compare variables between different groups with $p$ value $<.05$ set to represent significant difference and a value $p<.01$ set to represent highly significant difference. A comparative analysis of hemolymph associated cultivable bacterial diversity was represented using Classic Venn diagram (VennPainter_1.2.0.exe) to visualize the unique and shared set of bacteria with respect to different crab species (Lin et al., 2016). Diversity of hemolymph associated bacteria were analyzed by means of Simpson Index, D (Simpson, 1949), Shannon's index, H (Shannon and Weaver, 1949) and Pielou's evenness, J (Pielou, 1975) using PRIMER v6 (Primer-E Ltd., Plymouth, UK).

\section{Results}

\subsection{Sampling sites and morphometrics of crabs under study}

A total of 36 apparently healthy marine crabs ( 9 from each 4 different species namely, $C$. feriatus, $P$. pelagicus, $P$. sanguinolentus and $C$. lucifera) were used in the study (Fig. 1; Table 1). Average weight (W) and carapace width (CW) of the crabs were $51.89 \pm 15.96 \mathrm{~g}$ and $7 \pm 0.75 \mathrm{~cm}, 52.89 \pm 12.67 \mathrm{~g}$ and $9.06 \pm 1.42 \mathrm{~cm}, 43.78 \pm 11.70 \mathrm{~g}$ and $8.72 \pm 1.06 \mathrm{~cm}$ plus $52.33 \pm 18.5 \mathrm{~g}$ and $6.83 \pm 1.0 \mathrm{~cm}$ for $C$. feriatus, $P$. pelagicus, $P$. sanguinolentus and $C$. lucifera respectively. Corresponding hydrographical parameters of the sampling sites were given in Table 1.

\subsection{Culturable bacterial abundance in hemolymph of marine crabs}

Three different media were used for enumeration of cultivable heterotrophic bacteria from hemolymph. The results were represented as log colony forming units per $\mathrm{ml}$ of hemolymph ( $\left.\log _{10} \mathrm{CFU}\right)$. Overall, the $\log _{10} \mathrm{CFU} / \mathrm{ml} \pm \mathrm{SE}$ in the hemolymph of four crab species namely $C$. feriatus, $P$. pelagicus, $C$. lucifera and $P$. sanguinolentus were $4.18 \pm 0.05,4.16 \pm 0.02,4.11 \pm 0.04$ and $2.74 \pm 0.08$ in ZMA, $3.82 \pm 0.06,4.25 \pm 0.04,3.73 \pm 0.05$ and $2.12 \pm 0.09$ in BHIA, $3.11 \pm 0.06,2.66 \pm 0.04,4.01 \pm 0.03$ and $2.12 \pm 0.09$ in TCBS respectively. There was statistically significant difference between the viable bacterial counts of different crab species $(p<.05)$. Abundance of heterotrophic bacteria in the hemolymph was in the order of $C$. feriatus $>P . \quad$ pelagicus $>C . \quad$ lucifera $>P . \quad$ sanguinolentus; $P$. pelagicus $>C$. feriatus $>C$. lucifera $>P$. sanguinolentus and $C$. lucifera $>C$. feriatus $>P$. pelagicus $>P$. sanguinolentus in ZMA, BHIA and TCBS respectively (Fig. 2). Another noteworthy observation was the significant difference $(p<.05)$ existing in the mean CFUs between different growth media within the same crab sample.

\subsection{Diversity of culturable bacteria in hemolymph of marine crabs}

Diversity of hemolymph microbes in various wild caught marine crabs was examined through culture dependent methods. A total of 251 bacterial isolates were selected and characterized up to species level 


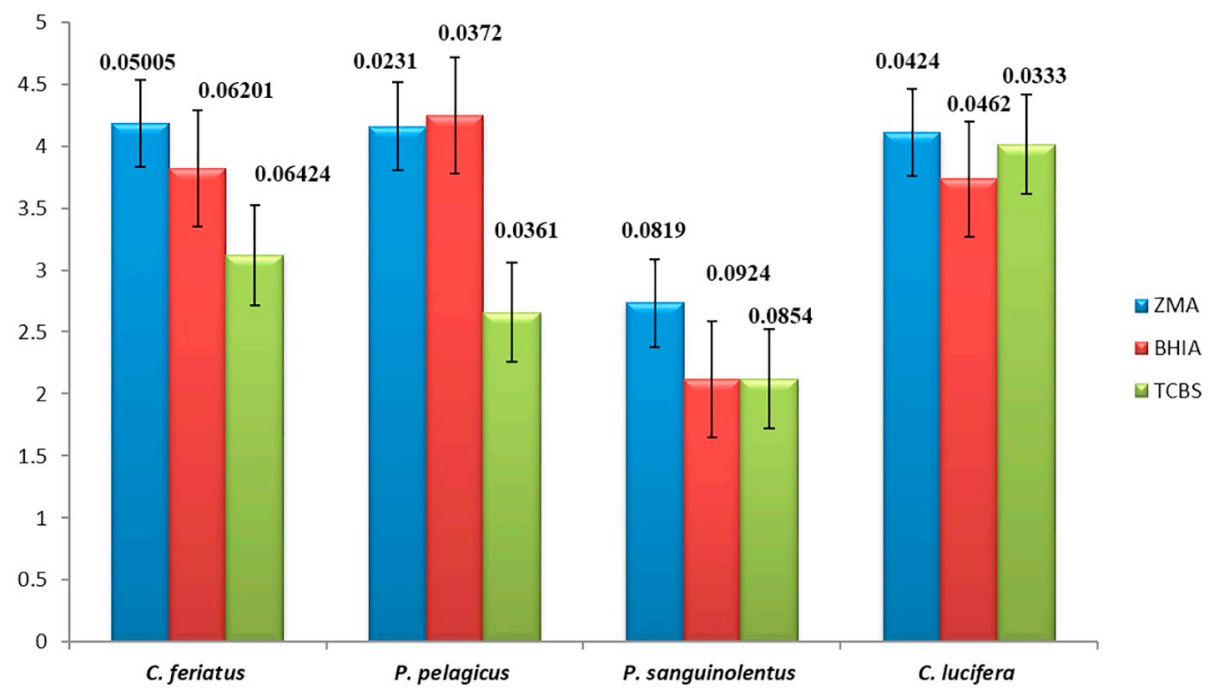

Fig. 2. Bacterial abundance in hemolymph of different crab species with respect to media used.

Observed means of log CFU \pm SE per $\mathrm{ml}$ of hemolymph.

based on polyphasic taxonomical approach comprising conventional microbiological tests (Bergey et al., 2012) and 16SrRNA gene sequencing (Janda and Abbott, 2007). The 16SrRNA gene sequences of each representative bacterial species were then submitted to GenBank (NCBI) and got assigned with accession numbers (MG792280MG792312). All together; we could identify 33 distinct bacterial species from 14 different genera. The most abundant bacteria genera were Vibrio (45\%) followed by Photobacterium (20\%), Staphylococcus (9\%) and Schewanella (9\%). Broadly, there were bacteria belonging to 2 major phyla namely, Proteobacteria (84\%) and Firmicutes (16\%). All identified bacterial species were classified in 7 different orders in which, Vibrionales (65\%) was the most abundant, followed by Bacillales (16\%), Alteromonadales (9\%), and Enterobacteriales (7\%). Family wise abundance was in the order of Vibrionaceae (65\%) > Staphylococcacea $(9 \%)>$ Shewanellaceae $(9 \%)>$ Enterobacteriaceae $(7 \%)>$ Bacillaceae $(7 \%)>$ Pseudomonadaceae $(1 \%)>$ Moraxellaceae/Aeromonadaceae (0.4\%). Overall, P. damselae (39\%) was the most abundant bacterial species which was followed by $V$. alginolyticus (36\%), V. brasiliensis (18\%) and $S$. haliotis (13\%). Three bacterial species namely, B. megaterium, $P$. damselae and $V$. alginolyticus were present in all four crab species (Fig. 3). There were 6 different Vibrio sp. which could not be assigned to any known species, were named as unidentified vibrios; that may represent some novel species. During phylogenetic analysis it was found that among these 6 unidentified vibrios, two belonged to Orientalis clade and rest 4 belonged to Harveyi clade (Fig. 4).

\subsection{Bacterial diversity in hemolymph of C. feriatus}

A total of 15 diverse bacterial species belonging to 9 genera were isolated from the hemolymph of $C$. feriatus. They were classified in two major phyla namely, Proteobacteria (90\%) and Firmicutes (10\%); under 5 different families in which Vibrionaceae (52\%) was the most abundant, followed by Shewanellaceae, Enterobacteriaceae, Bacillaceae and Staphylococcaceae. V. alginolyticus (25\%) was the most predominant species followed by $S$. haliotis and P. damselae (Fig. 5). The order Rhizobiales was present only in this crab species. Biodiversity indices of $C$. feriatus were depicted in Table 2.

\subsection{Bacterial diversity in hemolymph of $P$. pelagicus}

We could isolate 16 unique bacterial species belonging to 9 genera from $P$. pelagicus which were categorized into 2 major phyla namely, Proteobacteria (62\%) and Firmicutes (38\%). The family wise abundance was in the order of Vibrionaceae (46\%) $>$ Staphylococcacea $(27 \%)>$ Bacillaceae $(11 \%)>$ Enterobacteriaceae $(7 \%)>$ Pseudomonadaceae (5\%) > Moraxellaceae/Aeromonadaceae (1.8\%). Three bacterial families namely, Pseudomonadaceae, Moraxellaceae and Aeromonadaceae were present only in this crab species. At the same time, unlike other crab species, bacteria belonging to the family Shewanellaceae was absent. Biodiversity indices of $P$. pelagicus were illustrated in Table 2.

\subsection{Bacterial diversity in hemolymph of $P$. sanguinolentus}

Altogether, we could identify 12 distinct bacterial species from 6 genera, under two phyla i.e. Proteobacteria (87.5\%) and Firmicutes $(12.5 \%)$. They were classified under 4 different families in which, $83 \%$ were belonging to Vibrionaceae. The most abundant bacterial species was $V$. brasiliensis (29\%) which was followed by $P$. damselae and $V$. campbelliwith an abundance of $26 \%$ and $11 \%$ respectively (Fig. 5).

\subsection{Bacterial diversity in hemolymph of C. lucifera}

A total of 9 diverse bacterial species from 4 genera were isolated from this crab. There were two major phyla namely, Proteobacteria and Firmicutes; of which $95 \%$ were Proteobacteria. The identified bacterial species were classified under 3 different families in which Vibrionaceae (87. 5\%) was the most abundant, followed by Shewanellaceae $(7.5 \%)$, and Bacillaceae (5\%). V. alginolyticus (30\%) was the most predominant species followed by $P$. damselae (22.5\%) and V. campbelli $(12.5 \%)$ (Fig. 5).

\subsection{Antibacterial activity of hemolymph isolates}

All the 251 isolates were monitored for inhibitory activity against 11 aquatic pathogens (Table 3) by spot diffusion assay. Among these, 87 isolates (34\%) showed zone of clearance around inoculation spot for at least one pathogen. Antagonistic activity was exclusively observed against marine pathogens. Percentage of antagonistic isolates carried in hemolymph was in the order of $P$. pelagicus $(50 \%)>C$. feriatus $(35 \%)>P$. sanguinolentus $(31 \%)>$ C. lucifera $(20 \%)$. Maximum inhibition was observed against $V$. parahaemolyticus (35\%), followed by V. vulnificus (34\%), V. alginolyticus (33\%), B. cereus (32\%), V. anguillarum (29\%) and $V$. harveyi (27\%). However, inhibitory spectrum of hemolymph associated bacteria in each crab species was different (Fig. 6a). The highest inhibition was observed against $V$. harveyii, $V$. parahaemolyticus, V. vulnificus, B. cereus in C. feriatus, P. pelagicus, $P$. 


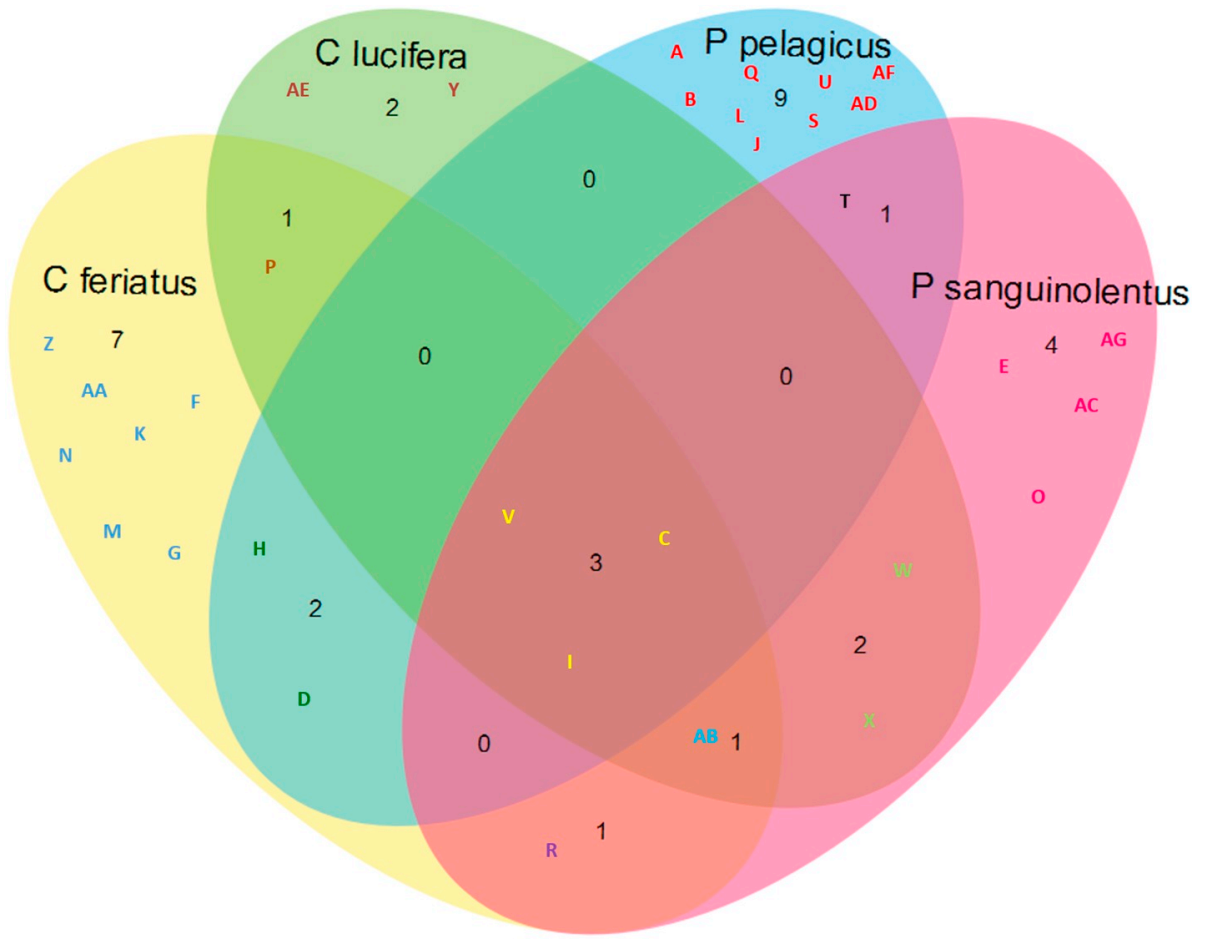

Fig. 3. Classic Venn diagram representing shared bacterial species among crab species.

Abbreviations: A: Acinetobacter baumannii; B: Aeromonas caviae; C: Bacillus megaterium; D: Bacillus cereus; E: Unidentified Enterovibrio; F: Enterobacter cloacae; G: Kluvera ascorbate; H: Pantoea dispersa; I: Photobacterium damselae; J: Proteus mirabilis; K: Proteus terrae; L: Pseudomonas aeruginosa; M: Unidentified Rhizobiales; N: Shewanella algae; O: Shewanella corallii; P: Shewanella haliotis; Q: Staphylococcus arlettae; R: Staphylococcus epidermidis; S: Staphylococcus haemolyticus; T: Staphylococcus pasteuri; U: Staphylococcus saprophyticus; V: Vibrio alginolyticus; W: Vibrio brasiliensis; X: Vibrio campbelli; Y: Vibrio harveyi; Z: Vibrio natriegens; AA: Unidentified Vibrio 1; AB: Vibrio parahaemolyticus; AC: Unidentified Vibrio 2; AD: Unidentified Vibrio 4; AE: Unidentified Vibrio 5; AF: Unidentified Vibrio 6; AG: Unidentified Vibrio 3. sanguinolentus and $C$. lucifera respectively. Inhibition against $V$. vulnificus was observed in all crab species under study. Based on activity score, $31 \mathrm{HL}$ isolated from $C$. feriatus was identified as a promising bacteria (score 11), followed by $88 \mathrm{HL}$ (score 9) from $P$. pelagicus. It was found that antagonistic activity of bacteria was strain specific, not species specific. Contribution of each species towards antagonistic activity against pathogens was calculated (Fig. 6b). It was found that isolates belonging to $P$. damselae were contributing utmost towards inhibition against tested pathogens namely, $B$. cereus, $V$. parahaemolyticus and V. vulnificus. Antagonism against $V$. anguillarum was shared by isolates of $S$. haliotis and $B$. megaterium. Similarly, inhibitory action against $V$. alginolyticus was contributed equally by isolates belonging to $B$. megaterium and $P$. aeruginosa. There were 10 different species showing antagonism against $V$. harveyi.

\section{Discussion}

Microbes that live within/upon animals have become an emerging area of research during recent years (Bahrndorff et al., 2016). The studies on microbial associations of vertebrates have provided various lines of evidence supporting the vital importance of these microbes for survival, homeostasis and development of hosts (McFall-Ngai et al., 2013). The close relationships between host and their microbes paved the way to 'hologenome theory of evolution' (Rosenberg et al., 2007). In contrast, scarce information is available on microbes associated with hemolymph in marine crabs; though they form a vital industry in several coastal countries (Bondad-Reantaso et al., 2012). Furthermore, the established presence of microorganisms in hemolymph of many healthy crustaceans (Wang et al., 2014), suggest that this ecosystem may contribute to host survival. Hemolymph microbes of some commercially important marine crabs have already been inspected for the presence of some human pathogens (Faghri et al., 1984; Mahalaxmi et al., 2013; Soundarapandian and Sowmiya, 2013), whereas its composition and role remain mostly unknown, especially on tropical marine crabs. Such data will be valuable to the field of microbial ecology and to reveal bacterial pathogenesis, host immunity, disease diagnosis and control during farming practices of many commercially significant species. Very recently, Zhang et al. (2018) revealed the real abundances and diversity of hemolymph microbiota in three aquatic invertebrates (Scylla paramamosain, Litopenaeus vannamei and Crassostrea angulata) through a new cell extraction method. However, they could not examine the role of these hemolymph microbes in host and could not point out any potential isolates for future applications due to the limitations of culture independent methods. Therefore, study was undertaken to analyse the abundance, diversity and role of cultivable hemolymph microbes of 4 commercially significant marine crab species (P. pelagicus, $C$. feriatus, $P$. sanguinolentus and $C$. lucifera); in its natural ecosystem through culture dependent methods.

Knowledge on the normal bacterial concentration in hemolymph (functional analogue of blood in vertebrates); where bacteria live under the pressure of an active immune system can be an important aspect of their health evaluation (Weiss and Aksoy, 2011). Therefore, enumeration of hemolymph bacteria was done as initial step. Even though occurrence of bacteria in crustacean's hemolymph had been previously inferred as disease (Lightner and Lewis, 1975), it is presently analyzed as a natural process (Gomez-Gil et al., 1998). In parallel to the observations on hemolymph of other crustacean species including crabs (Wang and Wang, 2015), our study also supported the non-sterile nature of hemolymph even in apparently healthy conditions. Additionally, the results showed that except $P$. sanguinolentus all other crabs under study, can bear higher bacterial concentration in hemolymph ( $>10^{4} \mathrm{CFU} / \mathrm{ml}$ ). Bacterial densities in excess of $10^{5} \mathrm{CFU} / \mathrm{ml}$ had been reported in hemolymph of blue crabs (Callinectes sapidus) in Galveston Bay, Texas (Davis and Sizemore, 1982) and Callinectes bocourti in Puerto Rico (Rivera et al., 1999). The variation in count may be attributed by the difference of species under study/area from where the crabs were collected. At the same time, cultivable bacterial concentrations in hemolymph were found to be individual- and speciesdependent; similar to the earlier observation of Desriac et al. (2014) on marine bivalves. Besides, a statistically significant interaction existing between growth media and $\mathrm{CFU} / \mathrm{ml}$ of hemolymph could be observed; signifying the scrutiny of media used while comparing the results of different studies. Since Vibrio sp. are reported as the dominant bacteria in hemolymph microbiota of marine animals (Colwell et al., 1975; Antunes et al., 2010; Albuquerque-Costa et al., 2013; Wang et al., 2014) specific enumeration for viable presumptive vibrios was done 


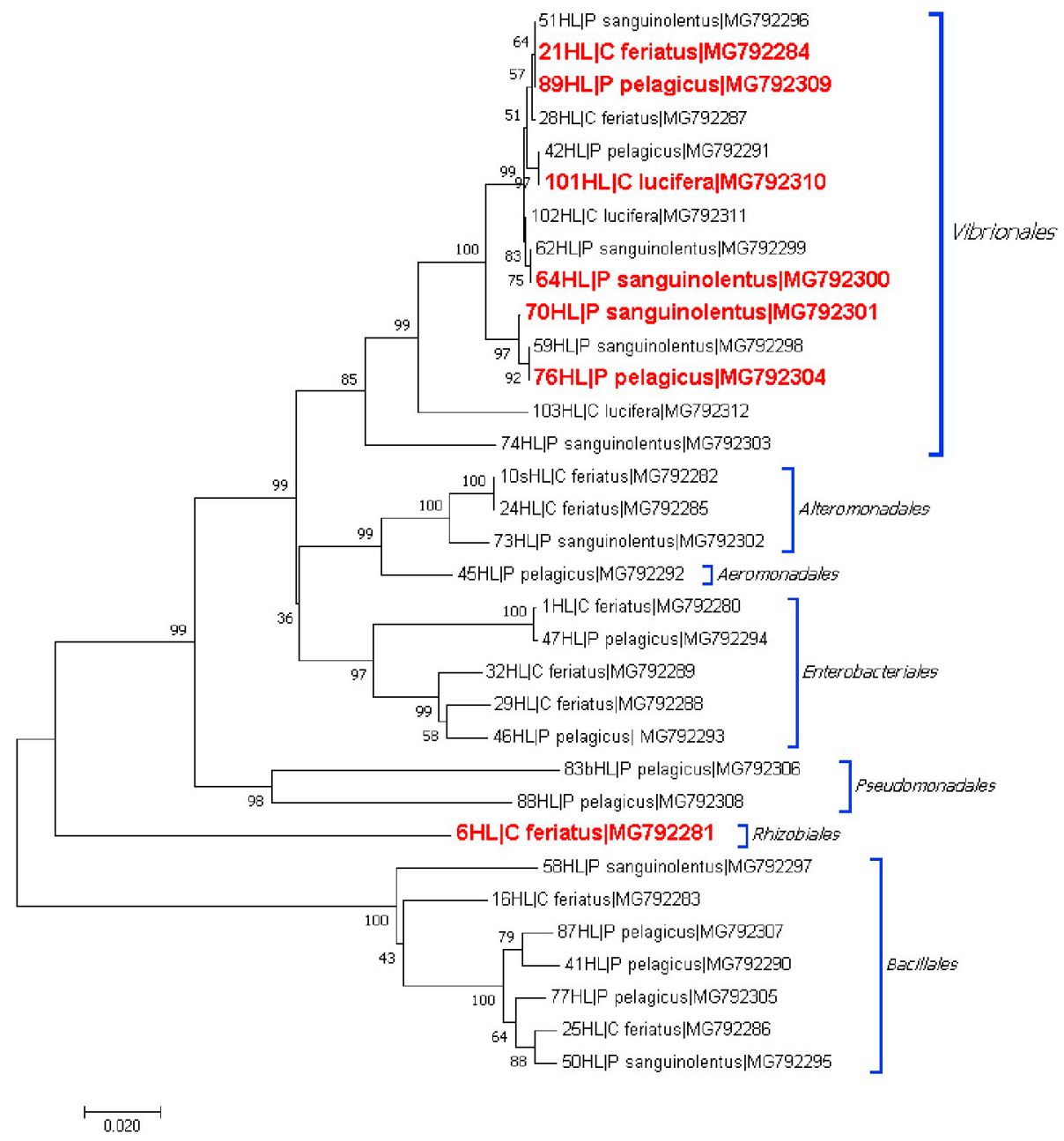

Fig. 4. Neighbor-joining tree of hemolymph isolates based on 16SrRNA gene sequence.

ID of representative isolate was followed by host and GenBank accession numbers. The probable novel bacteria were represented by red coloured bold letters. (For interpretation of the references to colour in this figure legend, the reader is referred to the web version of this article.)

(Bolinches et al., 1988). Abundance of vibrios was in the order of $C$. lucifera $>$ C. feriatus $>$ P. pelagicus $>$ P. sanguinolentus. While no data is available for comparison in same crab species, density of $10^{2}-10^{3} \mathrm{CFU} / \mathrm{ml}$ and $30-460 \mathrm{CFU} / \mathrm{ml}$ had been reported in hemolymph of Litopenaeus vannamei (Gomez-Gil et al., 1998; Albuquerque-Costa et al., 2013). More notably, TCBS count of $C$. lucifera was comparable to the count in non-selective media proposing that most of hemolymph isolates belonged to Vibrionacea.

Afterwards, bacterial diversity of hemolymph microbes was examined through culture dependent methods. Among 251 morphologically unique bacterial isolates selected for characterization, 33 distinct bacterial species (GenBank, NCBI accession numbers, MG792280MG792312) from 14 different genera belonging to 8 families and 2 major phyla could be identified. Gram negative isolates represented $84 \%$ of hemolymph microbes $(90 \%, 62.5 \%, 87.5 \%$ and $95 \%$ in C. feriatus, $P$. pelagicus, $P$. sanguinolentus and C. lucifera respectively); which is concurrent to the previous reports on other marine crustaceans and marine environments (Kaizu et al., 2011; Anwar and Choi, 2014; Wang et al., 2014). Altogether, the most abundant bacteria genera were Vibrio (45\%) followed by Photobacterium (20\%), Staphylococcus (9\%) and Schewanella (8\%). The other genera in the hemolymph included $\mathrm{Ba}$ cillus, Proteus, Pantoea, Kluyvera, Enterobacter, Enterovibrio, Pseudomonas, Acinetobacter and Aeromonas. Many of these were previously reported in hemolymph of other marine crustaceans collected from geographically distant sites (Colwell et al., 1975; Scott and Thune, 1986; Gomez-Gil et al., 2011; Wang et al., 2014), suggesting that they have established themselves as commensal in the hemolymph of marine crustaceans; may have significant roles in host survival. In contrast, the present study forms the first report of genera viz., Enterovibrio, Pantoea, Kluyvera and Enterobacter in crustacean hemolymph.

Abundance of Vibrio sp. in apparently healthy shrimp hemolymph ( $>60 \%$ of total count) had been reported by Wang et al. (2014). Vibrio was found as the most dominant genera in all 4 crab species; in the order of $C$. lucifera $(65 \%)>P$. sanguinolentus $(54 \%)>C$. feriatus $(38 \%)>P$. pelagicus $(27 \%)$. The results were in concordance with that of enumeration on TCBS agar; further emphasizing the suitability of this medium for specific enumeration for viable presumptive vibrios. Interestingly, within Vibrio, 12 species were identified, of which 6 could not be assigned to any known species. Therefore, the study indicated that even healthy adult marine crabs harbor diverse vibrios in hemolymph, of which some may represent potential novel Vibrio sp. Similarly, unidentified Vibrio sp. were reported in shrimp (Gomez-Gil et al., 1998) and spider crabs (Maja brachydactyla) (Gomez-Gil et al., 2010). Although Vibrio sp. had been documented as the predominant bacteria in hemolymph (Colwell et al., 1975; Sizemore et al., 1975), evidence of their pathological effects was well documented in literature (Wang, 2011). Particularly, species like V. alginolyticus, V. parahaemolyticus, V. harveyi are known pathogens in specific crab species (Wang, 2011; Keran-Bi et al., 2016); and their presence in apparently healthy animals suggests the possibility of their opportunistic nature. At the same time, constant and dominant occurrence of documented pathogens in healthy crab hemolymph might expand the current view on vibrio 


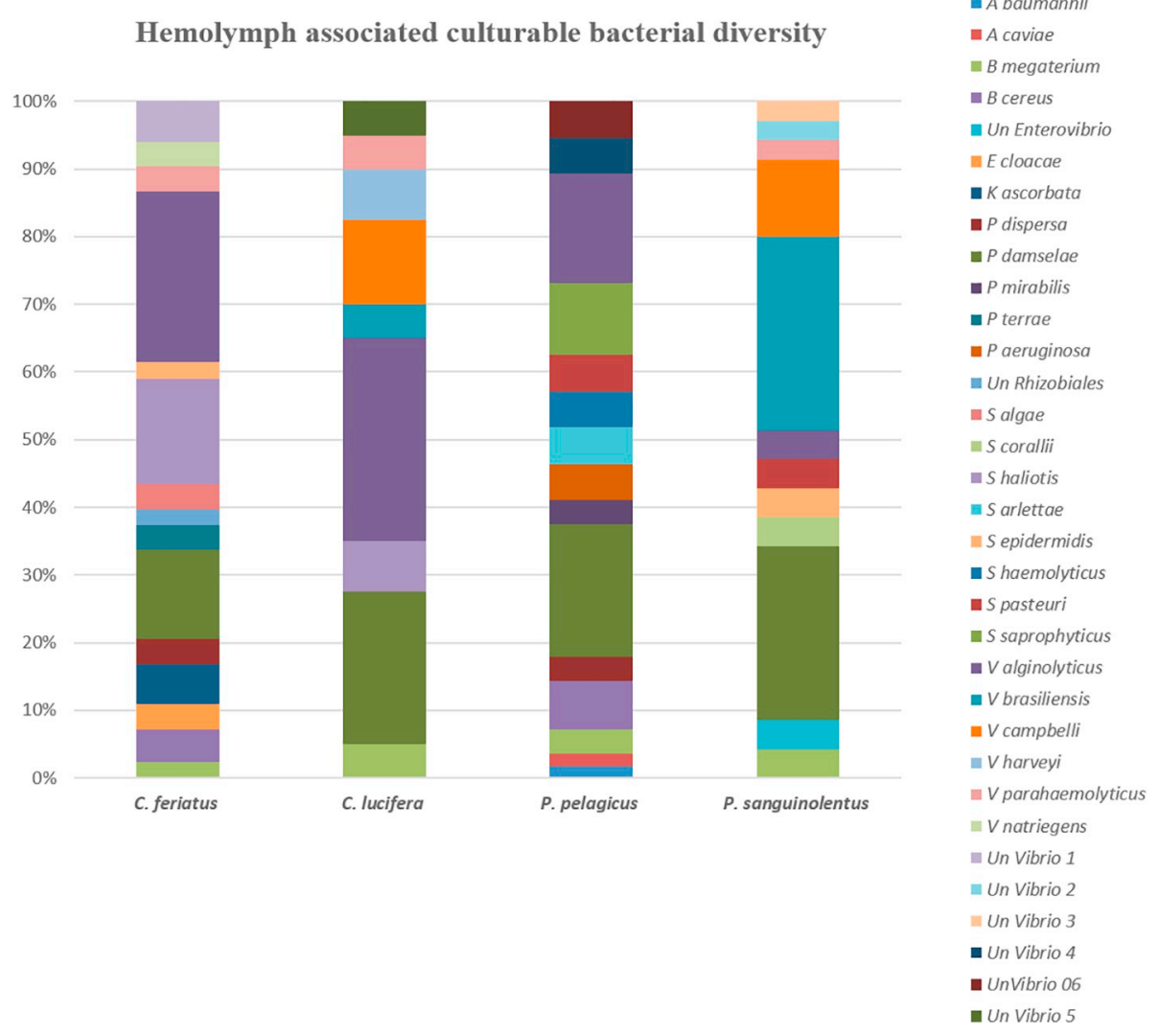

Fig. 5. Culturable bacterial diversity in hemolymph of individual marine crab species.

Table 2

Biodiversity indices of different crab species.

\begin{tabular}{lllllll}
\hline Crab species & $\mathrm{S}$ & $\mathrm{N}$ & $\mathrm{d}$ & $\mathrm{J}^{\prime}$ & $\mathrm{H}^{\prime}(\operatorname{loge})$ & 1-Lambda' \\
\hline C. feriatus & 15 & 33 & 4.004 & 0.913 & 2.472 & 0.9186 \\
P. pelagicus & 15 & 23 & 4.465 & 0.963 & 2.608 & 0.9605 \\
P. sanguinolentus & 11 & 27 & 3.034 & 0.8829 & 2.117 & 0.8803 \\
C. lucifera & 8 & 15 & 2.585 & 0.93 & 1.934 & 0.8952
\end{tabular}

Abbreviations: S: Total species; $\mathrm{N}$ : Total individuals; d: Species richness (Margalef); J': Pielou's evenness; $H^{\prime}\left(\log _{e}\right)$ : Shannon index; 1-Lambda': Simpson index.

Table 3

Aquatic pathogens used for the study.

\begin{tabular}{|c|c|c|}
\hline Bacteria & Strain ID & Source \\
\hline Bacillus cereus & MTCC 430 & $\begin{array}{l}\text { MTCC (Microbial Type Culture } \\
\text { Collection), Chandigarh }\end{array}$ \\
\hline Aeromonas veronii & CMFRI/AVe-01 & $\begin{array}{l}\text { ICAR-Central Marine Fisheries } \\
\text { Research Institute (CMFRI), Kochi }\end{array}$ \\
\hline Aeromonas hydrophila & MTCC1739 & MTCC, Chandigarh \\
\hline Photobacterium damselae & CMFRI/PhD-13 & CMFRI, Kochi \\
\hline Vibrio alginolyticus & 101 & $\begin{array}{l}\text { ICAR-Central Institute of Brackish } \\
\text { water Aquaculture (CIBA), Chennai }\end{array}$ \\
\hline Pseudomonas putida & MTCC102 & MTCC, Chandigarh \\
\hline Pseudomonas fluorescens & MTCC103 & MTCC, Chandigarh \\
\hline Vibrio anguillarum & $\mathrm{O} 1$ & CIBA, Chennai \\
\hline Vibrio parahemolyticus & MTCC 451 & MTCC, Chandigarh \\
\hline Vibrio vulnificus & MTCC 1145 & MTCC, Chandigarh \\
\hline Vibrio harveyi & 102 & CIBA, Chennai \\
\hline
\end{tabular}

pathogenesis.

Among 33 distinct bacterial species identified, P. damselae (39\%) was the most abundant one which was followed by $V$. alginolyticus (36\%), V. brasiliensis (17\%) and S. haliotis (13\%). Three bacterial species (B. megaterium, $P$. damselae and $V$. alginolyticus) were present in all crab species. However, each crab species was observed to carry a specific hemolymph microbiota (both in terms of abundance and diversity). The governing force for shaping hemolymph microbes in each crab species arouse interest and demands further research on the topic. The difference may be attributed by complex interaction between environment and feeding habits of each species. To get quantitative information on the diversity of hemolymph microflora of individual crab species, biodiversity indices were estimated. Both Simpson richness and Pielou's evenness ranged from $0.88-0.96$, signifying a moderate to high richness and comparatively higher evenness. Shannon's index was found to be varied from 1.93 to 2.6 indicating a moderate diversity (Clarke and Warwick, 2001). Among the 4 crab species under study, $P$. pelagicus showed the highest biodiversity indices.

To pave the way for some thoughtful insights on possible roles of hemolymph microbes in host welfare, inhibitory activity against aquatic pathogens were monitored. Out of 251 isolates screened, 87 isolates (34\%) demonstrated bioactivity against at least one pathogen strain used. In a study on hemolymph microbes of marine bivalves, Desriac et al. (2014) reported that about 3\% of hemolymph isolates showed clear inhibition against aquatic pathogens through agar diffusion assay using cell-free supernatants of culturable haemolymph-associated bacteria. Besides, $20 \%$ and $25-70 \%$ of cultivable bacteria from coral mucus (Ritchie, 2006; Shnit-Orland and Kushmaro, 2010) demonstrated antibiotic activity against pathogen strains through overlay with soft agar protocol and spot diffusion assay. The present study forms the first observation on inhibitory activity of crab hemolymph microbes against aquatic pathogens. Thus, current study raises the possibility that production and secretion of antimicrobial compounds by hemolymph associated bacteria forms a crab defense strategy, even though the same cannot be verified in the study. More interestingly, antagonistic activity was exclusively observed against marine pathogens, mostly Vibrio sp. to which marine animals are constantly encountered. Additionally, 
a

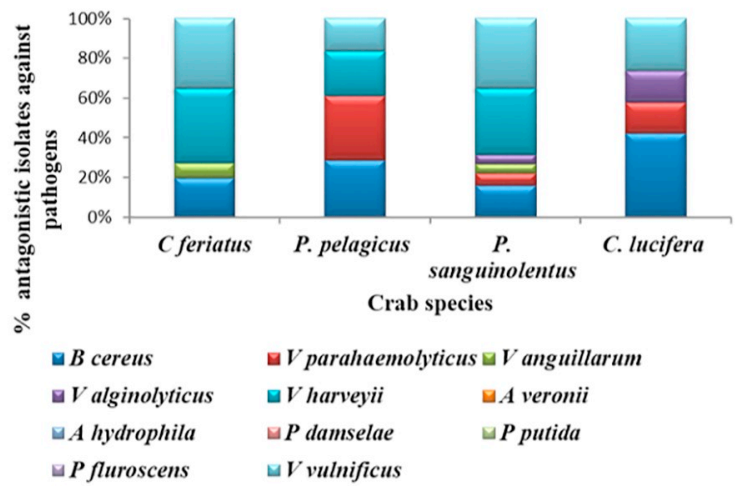

b

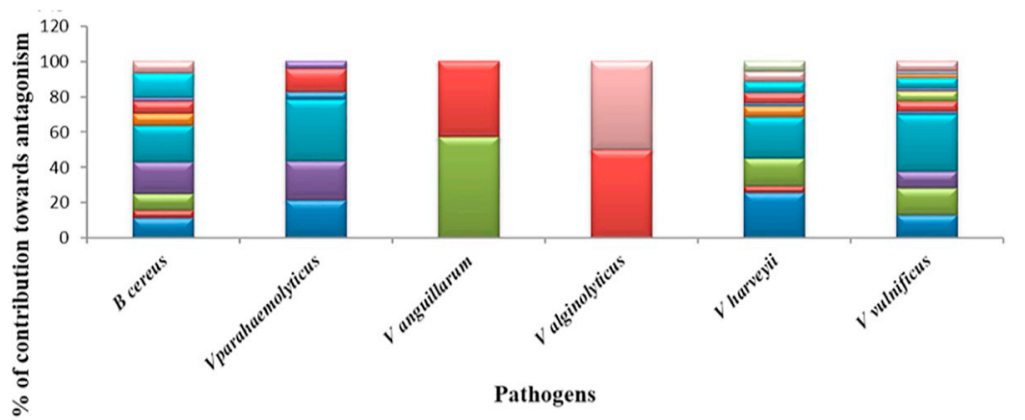

\begin{tabular}{|c|c|c|c|c|}
\hline$\square V$ alginolyticus & $\boldsymbol{\theta} P$ dispersa & $\boxplus$ Shaliotis & $\square$ cereus & $\square P$ damselae \\
\hline E cloacae & $\square$ A caviae & ㅁ megaterium & $₫ U n V 04$ & $\square S$ haemolyticus \\
\hline$\square$ S pasteuri & $\square A$ batmanii & $\square S$ arlette & $\square P$ aeuginosa & $\forall S$ saprophyticus \\
\hline
\end{tabular}

Fig. 6. Antibacterial activity of hemolymph isolates against aquatic pathogens. 6a: Inhibitory spectrum of hemolymph associated bacteria in each crab species. 6b: Contribution of each bacterial species towards antagonistic activity against aquatic pathogens.

inhibition against $V$. vulnificus was observed in hemolymph isolates of all 4 crab species, and we were unable to identify the same bacteria as an indigenous hemolymph microbe. All these suggest that antagonistic activity of bacteria may influence the diversity and prevalence of hemolymph microbes even though the same was not be substantiated through the present study. Simultaneously, presence of already known crab pathogens (such as $V$. alginolyticus, $V$. parahaemolyticus, $V$. harveyi) within hemolymph of apparently healthy marine crabs; advocate that the occurrence of these microbes in hemolymph may function as a mock/regular challenge to enhance the host immune system for generating basic immunity against these pathogens (Wang and Wang, 2015). The percentage of antagonistic isolates carried in hemolymph and their inhibitory spectrum varied between different crab species. The growth conditions, feeding habits, bacterial presence in surroundings (MearnsSpragg et al., 1998) and host susceptibility to different pathogens (Zhang et al., 2012) may contribute to these results. Nonetheless, potential of crab hemolymph microbes as a resource for antimicrobial agents is obvious, even if untapped.

\section{Conclusions}

In conclusion, our study supported the non-sterile nature of marine crab hemolymph even in apparently healthy conditions. Gram negative isolates were more predominant in hemolymph; with Vibrio as the principal genera. The exploration also revealed potential strains having applications for disease control in commercial aquaculture. Moreover, the results highlight marine crab hemolymph microbiota, to which little attention has been given, as a promising source for biological disease control agents having applications in aquaculture. Concurrently, the present study forms a reference data on culturable hemolymph microbes of 4 potentially important aquaculture crab species in apparently healthy conditions which can aid in the prediction of their health and disease diagnosis during farming practices. Further, the governing force for shaping hemolymph microbes in each crab species and possible role of antibacterial activities of haemolymph isolates in each crab defense arouse interest and demands further research on the topic.

\section{Conflicts of interest}

None.

\section{Acknowledgements}

The authors are grateful to the Head, Marine Biotechnology Division and the Director, ICAR-Central Marine Fisheries Research Institute,
Kochi for providing necessary facilities to carry out the present investigation. This work was supported by ICAR-CMFRI institute funded project "Health Management in selected finfish and shellfish \& bioprospecting from marine resources".

\section{References}

Albuquerque-Costa, R., Lima-Araújo, R., Fernandes-Vieira, S.R.H., 2013. Phenotyping of vibrios isolated from marine shrimp hemolymph. Cienc. Mar. 39, 317-321.

Antunes, F., Hinzmann, M., Lopes-Lima, M., Machado, J., Martins Da Costa, P., 2010. Association between environmental microbiota and indigenous bacteria found in hemolymph, extra-pallial fluid and mucus of Anodonta cygnea (Linnaeus, 1758). Microb. Ecol. 60, 304-309.

Anwar, M.A., Choi, S., 2014. Gram-negative marine bacteria: structural features of lipopolysaccharides and their relevance for economically important diseases. Mar. Drugs 12, 2485-2514.

Bahrndorff, S., Alemu, T., Alemneh, T., Nielsen, J.L., 2016. The microbiome of animals: implications for conservation biology. Int. J. Plant Genomics 1-7.

Bergey, D., Whitman, W., Goodfellow, M., Kaampfer, P., Busse, H., 2012. Bergey's Manual of Systematic Bacteriology. Springer, New York.

Bolinches, J., Romalde, J.L., Toranzo, A.E., 1988. Evaluation of selective media for isolation and enumeration of vibrios from estuarine waters. J. Microbiol. Methods 8, 151-160.

Bondad-Reantaso, M.G., Subasinghe, R.P., Josupeit, H., Cai, J., Zhou, X., 2012. The role of crustacean fisheries and aquaculture in global food security: past, present and future. J. Invertebr. Pathol. 110, 158-165.

Clarke, K.R., Warwick, R.M., 2001. A further biodiversity index applicable to species lists: variations in taxonomic distinctness. Mar. Ecol. Prog. Ser. 216, 265-278.

Colwell, R.R., Wicks, T.C., Tubiash, H.S., 1975. A comparative study of the bacterial flora of the hemolymph of Callinectes sapidus. Mar. Fish. Rev. 37, 29-33.

Davis, J.W., Sizemore, R.K., 1982. Incidence of Vibrio species associated with blue crabs (Callinectessapidus) collected from Galveston Bay, Texas. Appl. Environ. Microbiol. 43, 1092-1097.

Desriac, F., Le Chevalier, P., Brillet, B., Leguerine, I., Thuillier, B., Paillard, C., Fleury, Y. 2014. Exploring the hologenome concept in marine bivalvia: hemolymph microbiota as a pertinent source of probiotics for aquaculture. FEMS Microbiol. Lett. 350, 107-116.

Faghri, M.A., Perrington, C.L., Cronholm, L.S., Atlas, R.M., 1984. Bacteria associated with crabs from cold waters with emphasis on the occurrence of potential human pathogens. Appl. Environ. Microbiol. 47, 1054-1061.

FAO, 2014. The State of World Fisheries and Aquaculture, 2014. FAO, Rome. www.fao. org/3/a-i3720e.pdf (accessed 03 Jan 2018).

Gomez-Gil, B., Tron-Mayen, L.A., Roque, J.F., Turnbull, V., Inglis, A.L., Guerra-Flores, 1998. Species of Vibrio isolated from hepatopancreas, hemolymph and digestive tract of a population of healthy juvenile Penaeus vannamei. Aquaculture 163, 1-9.

Gomez-Gil, B., Roque, A., Lacuesta, B., Rotllant, G., 2010. Diversity of vibrios in the hemolymph of the spider crab Maja brachydactyla. J. Appl. Microbiol. 109, 918-926.

Gomez-Gil, B., Roque, A., Rotllant, G., Peinado, L., Romalde, J.L., Doce, A., 2011. Photobacterium swingsii sp. nov., isolated from marine organisms. Int. J. Syst. Evol. Microbiol. 61, 315-319.

Hovda, M.B., Lunestad, B.T., Fontanillas, R., Rosnes, J.T., 2007. Molecular characterisation of the intestinal microbiota of farmed Atlantic salmon (Salmo salar L.). Aquaculture 272, 581-588.

Janda, J.M., Abbott, S.L., 2007. 16 S rRNA gene sequencing for bacterial identification in the diagnostic laboratory: pluses, perils, and pitfalls. J. Clin. Microbiol. 45, 2761-2764.

Kaizu, A., Fagutao, F.F., Kondo, H., Aoki, T., Hirono, I., 2011. Functional analysis of C- 
type lysozyme in penaeid shrimp. J. Biol. Chem. 286, 44344-44349.

Keran-Bi, Zhang, X., Yan, B., Gao, H., Gao, X., Sun, J., 2016. Isolation and molecular identification of Vibrio natriegens from diseased Portunus trituberculatus in China. J. World Aquacult. Soc. 47, 854-886.

Kumar, S., Stecher, G., Tamura, K., 2016. MEGA7: Molecular evolutionary genetics analysis Version 7.0 for bigger datasets. Mol. Biol. Evol. 33, 1870-1874.

Lightner, D.V., Lewis, D.H., 1975. A septicemic bacterial disease syndrome of penaeid shrimp. Mar. Fish. Rev. 37, 25-28.

Lin, G., Chai, J., Yuan, S., Mai, C., Cai, L., Murphy, R.W., 2016. Venn painter: a tool for the comparison and identification of candidate genes based on Venn diagrams. PLoS One 11, e0154315.

Mahalaxmi, B., Revathy, K., Raghunathan, C., Anjalai, K., Subashini, A., 2013. Distribution of microbial population associated with crabs from Ennore seacoast Bay of Bengal north east coast of India. Int. J. Curr. Microbiol. App. Sci. 2, 290-305.

McFall-Ngai, M., Hadfield, M.G., Bosch, T.C.G., Carey, H.V., Domazet-Loso, T., Douglas, A.E., Dubilier, N., Eberl, G., Fukami, T., Gilbert, S.F., 2013. Animals in a bacterial world, a new imperative for the life sciences. Proc. Natl. Acad. Sci. U. S. A. 110 3229-3236.

Mearns-Spragg, A., Bregu, M., Boyd, K.G., Burgess, J.G., 1998. Cross-species induction and enhancement of antimicrobial activity produced by epibiotic bacteria from marine algae and invertebrates, after exposure to terrestrial bacteria. Lett. Appl. Microbiol. 27, 142-146.

Nair, A.V., Vijayan, K.K., Chakraborty, K., 2012. Diversity and characterization of antagonistic bacteria from tropical estuarine habitats of Cochin, India for fish health management. World J. Microbiol. Biotechnol. 28, 2581-2592.

Nandi, N., Gayen, K., Ghosh, S., Bhunia, D., Kirkham, S., Sen, S.K., Ghosh, S., Hamley, I.W., Banerjee, A., 2017. Amphiphilic peptide-based supramolecular, non-cytotoxic, stimuli-responsive hydrogels with antibacterial activity. Biomacromolecules 18, 3621-3629.

Noguerola, I., Blanch, A.R., 2008. Identification of Vibrio spp. with a set of dichotomous keys. J. Appl. Microbiol. 105, 175-185.

Pielou, E.C., 1975. Ecological Diversity. Wiley, New York.

Ponprateep, S., Tharntada, S., Somboonwiwat, K., Tassanakajon, A., 2012. Gene silencing reveals a crucial role for anti-lipopolysaccharide factors from Penaeus monodon in the protection against microbial infections. Fish Shellfish Immunol. 32, 26-34.

Ritchie, K.B., 2006. Regulation of microbial populations by coral surface mucus and mucus-associated bacteria. Mar. Ecol. Prog. Ser. 322, 1-14.

Rivera, A., Santiago, K., Torres, J., Sastre, M.P., Rivera, F.F., 1999. Bacteria associated with hemolymph in the crab Callinectes bocourti in Puerto Rico. Bull. Mar. Sci. 64, 543-548.

Rosenberg, E., Koren, O., Reshef, L., Efrony, R., Zilber-Rosenberg, I., 2007. The role of microorganisms in coral health, disease and evolution. Nat. Rev. Microbiol. 5 , $355-362$.

Scott, J., Thune, R.L., 1986. Bacterial flora of hemolymph from red swamp crawfish, Procambarus clarkii (Girard), from commercial ponds. Aquaculture 58, 161-165.

Shannon, C.E., Weaver, W., 1949. The Mathematical Theory of Communication. University of Illinois Press, Urbana.

Shnit-Orland, M., Kushmaro, A.S., 2010. Shewanella corallii sp. nov., a marine bacterium isolated from a Red Sea coral. Int. J. Syst. Evol. Microbiol. 609, 2293-2297.

Simpson, E.H., 1949. Measurement of diversity. Nature 163, 688.

Sizemore, R.K., Colwell, R.R., Thbiash, H.S., Lovelace, T.E., 1975. Bacterial flora of the hemolymph of the blue crab, Callinectessapidus: most probable numbers. Appl. Microbiol. 29, 393-399.

Soundarapandian, P., Sowmiya, S., 2013. Microbial Contamination of Commercially Important Crabs, Portunus pelagicus (Linnaeus) and P. sanguinolentus (Herbst). vol. 2. pp. 593.

Tubiash, H.S., Sizemore, R.K., Colwell, R.R., 1975. Bacterial flora of the hemolymph of Blue crab, Callinectes sapidus- most probable numbers. Appl. Microbiol. 29, 388-392.

Varadharajan, D., Soundarapandian, P., 2014. Proximate composition and mineral contents of freshwater crab Spiralothelphus ahydrodroma (Herbst, 1794) from Parangipettai, South East Coast of India. J. Aquac. Res. Dev. 5, 1-6.

Verschuere, L., Rombaut, G., Sorgeloos, P., Verstraete, W., 2000. Probiotic bacteria as biological control agents in aquaculture. Microbiol. Mol. Biol. Rev. 64, 655-671.

Wang, W., 2011. Bacterial diseases of crabs: a review. J. Invertebr. Pathol. 106, 18-26.

Wang, X.W., Wang, J.X., 2015. Crustacean hemolymph microbiota: Endemic, tightly controlled, and utilization expectable. Mol. Immunol. 68, 404-411.

Wang, X.W., Xu, J.D., Zhao, X.F., Vasta, G.R., Wang, J.X., 2014. A shrimp C-type lectin inhibits proliferation of the hemolymph microbiota by maintaining the expression of antimicrobial peptides. J. Biol. Chem. 289, 11779-11790.

Wang, G., Mishra, B., Lau, K., Lushnikova, T., Golla, R., Wang, X., 2015. Antimicrobial peptides in 2014. Pharmaceuticals (Basel) 8, 123-150.

Weiss, B., Aksoy, S., 2011. Microbiome influences on insect host vector competence. Trends Parasitol. 27, 514-522.

Winkler, L., 1888. Die Bestimmung des in Wasser Gelösten Sauerstoffes. Berichte der Deutschen Chemischen Gesellschaft 21, 2843-2855.

Zhang, J., Zhang, Y., Liu, S., Han, Y., Zhou, Z., 2012. Modelling growth and bacteriocin production by Pediococcus acidilactici PA003 as a function of temperature and $\mathrm{pH}$ value. Appl. Biochem. Biotechnol. 166, 1388-1400.

Zhang, X., Sun, Z., Zhang, X., Zhang, M., Li, S., 2018. A new cell extraction method reveals hemolymph microbiome of three aquatic invertebrates. Appl. Environ. Microbiol. https://doi.org/10.1128/AEM.02824-17. 